\title{
A culinária como objeto de estudo e de intervenção no campo da Alimentação e Nutrição
}

\author{
Culinary as an object of study and intervention \\ in the field of Food and Nutrition
}

Rosa Wanda Diez-Garcia ${ }^{1}$

Inês Rugani Ribeiro de Castro ${ }^{2}$

\footnotetext{
${ }^{1}$ Departamento de Clínica M édica, Faculdadede M edicina de Ribeirão Preto, Universidade de São Paulo. Av. dos Bandeirantes 3.900 M onte Alegre. 14049-900 Ribeirão Preto SP. wanda@fmrp.usp.br ${ }^{2}$ Programa de PósGraduação em Alimentação, Nutrição eSaúde, Instituto deNutrição, U niversidade do Estado do Rio deJ aneiro.
}

Abstract Culinary is approached here as an object of food and nutritional studies and interventions aimed at dietary changes. In order to explore the culinary potential, two studies are presented: one qualitative, focusing on dietary intake, with subjects from two socioeconomic sectors submitted to salt restrictions; the other uses cooking as structural axis of an educational method for promoting healthy eating. In both studies one can observe the potential of culinary: in the first, as a medium which allows access to information about food procedures that can improve the quality of information about food intake and food practices and, in the second, as an effective space for interventions aimed at food habit changes by addressing their sensorial, cognitive, symbolic and procedural dimensions.

Key words Culinary, Nutrition education, Food anthropology, Cooking
Resumo A culinária éaqui abordada como obje to de estudos alimentares e nutricionais e de intervenções que visem a mudanças alimentares. Para explorar este potencial da culinária, dois estudos são apresentados: um qualitativo, voltado para a análise do consumo alimentar, com sujeitos de dois segmentos socioeconômicos, submetidos à restrição de sal; e outro que recorre à culinária como ei xo estruturante de um método educativo para a promoção da alimentação saudável. Em ambos os estudos pôde-se constatar o potencial da culinária: no primeiro, como um meio que permite acessar informações sobre procedimentos com alimentos que podem melhorar a qualidade da informação sobre o consumo e as práticas alimentares; e no segundo, como um espaço eficaz para intervenções que visem a mudanças alimentares por abordar suas dimensões sensoriais, cognitivas, simbólicas e práticas. Palavras-chave Culinária, Educação nutricional, Antropologia da alimentação, Alimentação 
A culinária como objeto de estudo

A culinária pode ser entendida como qualquer tipo de processamento de transformação do alimento ou pode ser considerada a partir da passagem da ingestão de alimentos crus para cozidos. N este caso, o uso do fogo, dominado pelo homem cerca de 500 mil anos a.C., passa a ser seu marco inaugural ${ }^{1-3}$.

I números procedimentos de manipulação do alimento sem recorrer ao fogo facilitaram sua digestão, diversificaram o uso dos recursos alimentares, afetaram o tempo gasto para a sua ingestão e possibilitaram o seu armazenamento. Por exemplo: pendurar a carne ao relento e deixá-la apodrecer um pouco é uma maneira de processá-la e modificar sua constituição e digestibilidade; secar 0 alimento ao vento; enterrá-lo para provocar sua fermentação; batêlo; cortálo; macerá-lo; coá-lo‥ Contudo, o processamento do alimento pelo fogo estabeleceu mudanças profundas na alimentação humana. Aumentou a disponibilidade de energia, facilitou a mastigação de sementes e de outros vegetais ricos em fibras, assim como de carnes, cheias de músculos e tecido conectivo, aumentou seu tempo de conservação, permitiu proteção contra infecções e diminuiu a toxicidade de certos vegetais. Discute-seinclusi ve o papel do cozimento no processo evolutivo. 0 cozimento pode ter sido essencial para garantir um aporteenergético que seria inalcançável com alimentos crus. Isso significa que biologicamente o homem pode ter sido adaptado, com dentes menores, trânsito intestinal rápido, para a ingestão de alimentos cozidos, com menor teor de fibra 4 . A importância da culinária também éreconhecida para a organização social. Foi atribuído a ela o papel de organizar a sociedade, introduzir responsabilidades, compartilhamentos e laços sociais que se estabeleceram com o preparo da comidal, ${ }^{1,3}$.

A palavra culinária vem do latim culinarius, quederiva da palavra culina, que quer dizer cozinha. Diz respeito à arte de cozinhar e pode ser caracterizada por um conjunto de aromas e sabores peculiares a uma dada cultura. Trata-se de um fenômeno estritamente cultural que diferencia o homem dos demais animais. Fieldhouse ${ }^{5}$ refere-se à cozinha como um estilo de cozinhar que caracteriza a comida de um grupo. Nela se inclui a sel eção dealimentos e a frequência de seu uso ${ }^{6}$, as técnicas de preparo e a produção de sabores particulares, organizadas e orientadas por regras referentes à aceitabilidade, adequação de pratos a situações de rotina e a momentos espe- ciais e, ainda, aos seus usos simbólicos ${ }^{7}$. Classificações, taxonomias particulares e regras complexas que abrangem todas as etapas do manejo da comida estão presentes nas culinárias. Tais regras, culturalmente elaboradas, são interiorizadas pelo indivíduo de modo inconsciente, possuindo padrões de ordenamento e compatibilidade, de exclusão e inclusão.

$\mathrm{Na}$ perspectiva antropológica, a culinária pode ser analisada como produto da interação do homem com seu ecossistema, resultante de diferentes soluções que grupos humanos deram para a sua alimentação $0^{8,9}$, integrada a um sistema simbólico que, segundo autores como Radcliffe-Brown e Malinowski, cumpre funções sociais e econômicas ${ }^{10}$. M esmo que valores simbólicos agregados tenham se originado, ao longo do tempo, por necessidades pontuais de ordem ecológica, tecnológica, econômica ehistórica, entre outras, eles passam a sobreviver independentemente, constituindo-se parte daquela culinária ${ }^{7,11,12}$. Neste sentido, os padrões alimentares humanos são resultantes da relação dos homens entre si e com a natureza, da aprendizagem e da herança cultural ${ }^{13}$.

Para a antropologia estrutural, trata-se deuma manifestação que, tal como outros domínios culturais, como a linguagem ea arte, expressa inconscientemente a estrutura de uma dada sociedade ${ }^{14}$.

$\mathrm{Na}$ perspectiva da bioquímica, o processamento e a combinação de alimentos promovem um diversificado aporte de nutrientes e de compostos bioativos que desempenham diferentes funções biológicas, tornando-se, assim, um objeto complexo de análise química e nutricional. Os efeitos associados a um alimento podem estar relacionados com diversos de seus componentes ou com procedimentos relacionados a ele. Efeitos deantagonismo esinergismo desencadeados pelo processamento e pela combinação de alimentos podem, por exemplo, alterar a biodisponibilidade original de seus nutrientes. Cada culinária inclui, portanto, um complexo de ele mentos e interações químicas ${ }^{15}$.

Situada entre a natureza e a cultura, a alimentação porta, de um lado, as propriedades nutritivas atendendo às necessidades biológicas do homem e, de outro, o comportamento alimentar de grupos sociais intimamente entranhados no sistema sociocultural. Do ponto de vista nutricional, a diversidade alimentar é uma das garantias de uma dieta equilibrada por possibilitar o aporte necessário de macro e micronutrientes. Diferentes conjuntos alimentaresforam resultantes dos vários caminhos en contrados pelo 
homem para satisfazer suas necessidades alimentares e nutricionais ${ }^{11}$.

Uma hipótese sobre a função primordial da culinária é a de que ela seria estratégica para que o homem convivesse com dois polos antagônicos, a neofilia ea neofobia al imentar, ambos parte do que Rozin eVollmecke ${ }^{16}$ denominaram de" paradoxo do onívoro". Analisada por este princípio, ela serviria para atenuar as incompatibilidades decorrentes deste convívio. Tanto a necessidade de diversificar as fontes al imentares (neofilia) como o medo de um alimento novo e desconhecido pelo potencial risco que oferece (neofobia) podem ter atuado, ao longo do processo evolutivo, como propulsores da constituição da culinária que, de um lado, incorpora alimentos novose, de outro, os torna familiares por incluílos em um registro identificado de sabores, gerado por procedimentos reconhecíveis daquelaculinária ${ }^{16,17}$. Tais procedimentos possibilitam atenuar o desconforto provocado por um alimento desconhecido.

0 registro sensorial de uma culinária, definido como o resultado de um complexo de sensações geradas pelo gosto, aroma, temperatura e tato, a torna reconhecida pela familiaridade com os seus sabores. Estes, quando reconhecíveis, se caracterizam como marca típica de caráter olfato-gustativo, compondo a personalidade de de terminada cozinha ${ }^{16}$. Assim, ao passar pelas re gras convencionais de um dado sistema culinário, o alimento passa a ser parte deste. De certa forma, esse percurso do alimento pela culináriaé uma passagem da natureza à cultura, ou seja, um trajeto dereconhecimento decorrente da ação humana?.

Nessa perspectiva, o gosto, sensação experimentada pelas papilas gustativas, intimamente relacionado ao olfato, éapreendido culturalmente e desempenha papel fundamental na orientação de escolhas alimentares. A sensação e a percepção ligam os mundos físico e psicológico. Para entender os estímulos externos, o organismo necessita de informações fornecidas pelos órgãos do sentido, por meio de impulsos elétricos e sinais químicos (sensação), e da transmissão delas ao cérebro. A percepção é o processamento, a organização e a interpretação desses estímulos ${ }^{18}$. Deste modo, a percepção é norteada pela bagagem deexperiências anteriores, inexoravelmente culturais. Os sistemas perceptivos estão intimamente ligados à aprendizagem, memória, emoção e linguagem ${ }^{19}$. 0 gosto desempenha também um papel fisiológico, pois aciona reflexos de ingestão e digestão; ativa o sentimento de prazer e a saciedade e detecta a qualidade do alimento (deterioração, toxicidade) ${ }^{20}$.

Brillat-Savarin ${ }^{21}$, em seu tratado sobre a fisiologia do gosto, editado em 1848, considera que o gosto promove três diferentes sensações: a sensação direta, que éa primeira percepção quese dá no contato do alimento com a boca; a sensação completa, que é a que ocorre quando o alimento passa para o fundo da boca, liberando seu gosto e perfume; e, por último, a sensação refletida, que é o juízo que a alma faz sobre as impressões que Ihe são transmitidas. 0 interessante desta análise é a separação das sensações, particularmente a terceira, que se refere à interpretação das sensações mencionadas previamente.

Apesar de a sensação do gosto estar circunscrita à boca, aspectos cognitivos desempenham um papel na apreciação que pode influenciar o gosto. Experimentos em que foram utilizados corantes insípidos em um mesmo alimento demonstraram que eles desencadearam reações distintas em degustadores experientes, influenciados pela cor. Uma revisão do conceito do gosto foi reivindicada por Hervé This ${ }^{22}$, que o considera uma sensação sintética mais ampla do que a percebida pelas papilas gustativas. Envolve as sensações gustativas, olfativas, mecânicas, proprioceptivas (capacidade de reconhecimento e localização espacial do corpo sem o uso da visão) e térmicas que permitem perceber o gosto, sentido de maneira fisiológica, e enviar informações para o cérebro, que o interpreta e associa a ele qualidades segundo a experiência individual e coletiva, relacionada a lembranças, emoções, aprendizagem, familiaridade etc. ${ }^{22}$. As manifestações familiares eas primeiras experiências são marcantes e constituem estruturas que serão as matrizes de percepção e apreciação de ações ${ }^{23}$. Esses elementos nos levam a considerar a alimentação como repertório de uma culinária, um exemplo contundentede como a experiência cultural fica marcada biologicamente e integrada na psique ${ }^{19}$.

Partindo dessas considerações, assume-se como culinária um conjunto de regras relacionadas à alimentação, tais como os alimentos mais usados (frequência de uso); aqueles queconstituem a base da alimentação e os complementares; regras sobre a constituição das refeições; a estrutura dos cardápios cotidiano e festivo; as possíveis combinações alimentares; as técnicas de preparo (modalidades de corte, de cozimento, de hierarquização dos procedimentos, 0 arranjo de gruposdeingredientes, os utensíliosapropriados), os temperos principais e secundários que proporcionam os sabores mais marcantes; as for- 
mas de apresentação e de servir; as regras relativas à apropriação de alimentos específicos à situação e aos seus usos. Esse conjunto de características permiteidentificar a culinária de uma região ou nação como uma particularidade reconhecida e familiar que provoca sentimentos de pertencimento ou de alteridade a uma cultura ${ }^{24}$.

Abordar a alimentação na perspectiva da culinária, inserida em um complexo de taxonomias e ordenações, contextualiza padrões alimentares em um conjunto de procedimentos e valores que melhor traduz a complexidade desse fenômeno. Os valores simbólicos atribuídos aos alimentos e rituais que envolvem a alimentação, que orientam a apreciação e, portanto, influenciam diretamente 0 consumo de alimentos ofere cem uma perspectiva de análise ampliada para o conhecimento deum dado perfil al imentar. Esses val ores apresentam nuances e expressam peculiaridades de grupos e segmentos sociais influenciados por aspectos ideológicos, étnicos, socioeconômicos, entre outros. Como objeto de estudo, a culinária pode trazer uma importante contribuição para o campo da alimentação e nutrição, uma vez que trata a alimentação como um sistema organizado.

\section{A culinária como expressão de diferenças sociais na alimentação}

Um estudo qualitativo abordando alguns aspectos da culinária de dois conjuntos de famílias de diferentes condições socioeconômicas éaqui apresentado como exemplo do potencial deste objeto para análise das diferenças sociais, expressas na alimentação, que podem ficar embotadas se a alimentação for abordada puramente por meio de instrumentos clássicos como os inquéritos alimentares que visam conhecer o padrão alimentar. No estudo aqui descrito, uma condição especial se impunha às expressões culinárias familiares, os entrevistados estavam submetidos à restrição de sal por serem portadores de hipertensão arterial. Deste modo, a preocupação deste estudo foi conhecer o impacto da incorporação da restrição alimentar pela família, focalizando aspectos da culinária sob condições restritivas ao uso do sal e entendendo este procedimento como uma manifestação de autocuidado. Foram estudadas trinta famílias de uma cidade deum milhão de habitantes no interior do estado de São Paulo, Brasil, sendo que metade apresentava condições socioeconômicas das classes populares, com renda per capita concentrada predominantemente entre 0,5 e 1,0 salário mínimo e baixa escolaridade (Grupo 1). A outra metade (Grupo 2), com características de classemédia, apresentava escolaridademais alta e renda per capita mínima de 3,5 salários mínimos $(80 \%$ dos entrevistados tinham renda de até 9,0 salários mínimos). A idade média dos membros da família que portavam hipertensão erade 57,6 (dp 9,0 emediana 58,5) anos. Asinformações foram obtidas por meio de entrevista semiestruturada e inquérito alimentar com uma abordagem qualitativa ${ }^{25}$.

A estrutura do almoço e do jantar era constituída por uma "base" - arroz e feijão; e uma "mistura", termo usado para referir-se a preparações com carne, vegetais ou massas. A pesar de ser parte da rotina, a "mistura" nas classes populares nem sempre estava disponível e, com mais frequência, era distribuída com parcimônia entreos membros da família. A variedade ea ênfase nas "misturas" nas famílias do Grupo 2 contrastaram com o peso atribuído ao arroz efeijão nas famílias do Grupo 1, apesar de esta combinação fazer parte da rotina de ambos os grupos. Nas famílias com menos recursos financeiros, a proporção média era de 3,6 partes de arroz para 1,0 de feijão e, nas com mais recursos, 1,9 parte de arroz para 1,0 de feijão, avaliados pela disponibilidade per capita desses alimentos na família.

A "mistura" foi marcada, no Grupo 1, pelo comedimento e, no Grupo 2, pela variedade e fartura. A condição econômica também definiu o predomínio dos tipos de cortes das carnes. 0 Grupo 2 usava vários tipos de carnes (bovina, suína, frango, peixe) e, quando se referia ao frango, mencionava a coxa, a sobrecoxa e o peito. Já asfamílias do Grupo 1 utilizavam principalmente 0 frango inteiro e também suas partes menos nobres, como pescoço, pée carcaça. Sardinha em lata, ovo "batidinho" e linguiça foram outras "misturas" frequentes nesse grupo.

No desjejum do Grupo 1, predominou o café puro ou com leite e pão puro ou com margarina; no Grupo 2, além destes, foi observada a presença dequeijo, presunto, sucos efrutas, outros tipos de pães (deforma eintegral), iogurtee cereais em flocos. No almoço, o arroz e o feijão estiveram presentes à mesa da metade dos entrevistados de ambos os grupos; já os vegetais predominaram no segundo grupo. No jantar, houve com maior frequência o consumo de lanches no Grupo 2.

Nos relatos a seguir, são evidenciadas as limitações que se apresentam na escolha do tipo de carne, da "mistura" e no custo que representa um lanchecomo opção degranderefeição, fundamentando a manutenção do jantar mais convencional. 
Eu tô comprando o mais barato. Coxa não, coxa émuito caro, sobrecoxa émuito caro. Eu gosto muito mesmo é de pé de frango. Pé de frango é barato. Não sei se aquela pele faz mal. Se tirar a pele também não tem ... é pescoço, carcaça, étudo mais barato.

E como entra pouco dinheiro, a senhora vai vendo. Eu tenho coisas, faço bolinho uma coisa, faço outra misturinha, outra misturinha, vai tocando a vida desse jeito.

0 lanchefica, porquea pessoa nunca come um lanche só, dependendo o lanche, né? Pizza que era daqui do meu vizinho, quando a gente pegava, quando estavam todos aqui, pegava umas três pizza grande. Ah, não rende, então eu acho que é melhor vocêfazer um arroz efeijão, querendemais.

0 envolvimento com o preparo da comida também foi diferente entre os grupos. Foi inegável o impacto da pobreza na restrição do repertório de ingredientes, limitando as possibilidades culinárias. Entretanto, ficaram também evidentes as diferenças na lida com a comida entre famílias com a mesma condição social. Havia entrevistados que, mesmo em um contexto de restrição, tinham um repertório culinário mais diversificado e manifestavam mais interesse e cuidados com a comida.

Foi frequente em todas as famílias estudadas o uso de temperos industrializados no formato de tabletes ou misturados ao sal. Pimenta-doreino, alho, cebola, cheiro-verde (salsinha e cebolinha) e orégano foram os temperos mais relatados pelas famílias do Grupo 1 . Além desses, as famílias do Grupo 2 mencionaram coentro, cominho emolhos depimenta, entreoutros. Foi observado o uso de maior quantidade de sal pelas famílias mais pobres (disponibilidade diária per capita de $12,0 \pm 5,2 \mathrm{~g}$ de sal) em relação às de classe média (7,3 $\pm 3,9 \mathrm{~g}$ ). Tal diferença também foi encontrada com o óleo $(43,5 \pm 25,0 \mathrm{ml}$ e $31,5 \pm 20,5 \mathrm{ml})$ e com o açúcar (93,0 $\pm 44,0 \mathrm{~g} \mathrm{e}$ $32,0 \pm 22,0 \mathrm{~g}$ ).

0 uso excessivo, segundo os referenciais científicos biomédicos, de sal, açúcar e óleo seria uma forma de acentuar o gosto da comida, de deixá-la mais "forte", categoria associada à saciedade, resistência física e inclusive moral (referente ao caráter da pessoa) ${ }^{26}$. Ressalta-se que, em ambos os grupos familiares, havia pelo menos uma pessoa submetida à restrição de sal, para quem a recomendação de consumo individual deve ser menor que $6,0 \mathrm{~g}$ de sal por $\mathrm{dia}^{27}$. Foi mais frequente 0 uso de gordura animal pelas famílias mais pobres, possivelmente pelo fato de a maioria deles ser de origem rural.
Narrativas que denotaram o gosto por comer e pela comida desde o seu preparo podem indicar um atributo diferenciado do comportamento alimentar pelas possibilidades simbólicas intrínsecas a esta prática, particularmente a do autocuidado. Esse gosto pela culinária, manifestado tanto por quem faz quanto por quem aprecia, é uma forma de agregar pessoas, de prover cuidado aos destinatários das preparações, e é um prazer estético e sensorial.

0 investimento no preparo da comida, na busca de novas receitas, foi mais frequente no Grupo 2, apesar de o repertório de preparações ter sido semelhante e restrito em ambos. M acarronada, churrasco, frango assado, salada com maionese e lasanha foram as preparações mais frequentes de fim de semana. Entre as famílias do Grupo 1, foi comum o consumo de massa como "mistura", junto ao arroz e o feijão.

A transmissão de conhecimento do repertório culinário nos grupos estudados foi principalmente a tradicional, entre gerações de mulheres, por meio da observação. As entrevistadas e algumas das esposas dos entrevistados aprenderam a cozinhar vendo a mãe fazer e assumindo certas tarefas do preparo da comida. As que não aprenderam antes do casamento o fizeram depois, por pressão do marido e da necessidade de responder a esta responsabilidade. Três entrevistadas das famílias do Grupo 1 aprenderam a cozinhar com as patroas, quando trabal havam como domésticas. Uma das entrevistadas, como trabal hava antes de se casar, aprendeu por meio de receitas e com a sogra, e apenas uma mulher referiu o uso de livros e de curso de culinária no seu processo de aprendizagem. Devido à mudança da dinâmica detransmissão desseconhecimento - dada pela redução do contato entre gerações, pela participação da mulher no mercado de trabalho e a sua escolarização -, interven ções que capacitem pessoas para terem autonomia no preparo da alimentação, que as sensibilizem e subsidiem para entender melhor sua relação com a comida eque ampliem o investimento na al imentação domiciliar podem ser uma estratégia de programas de alimentação e nutrição que venha a influenciar a qualidade al imentar de famílias.

A condição de restrição de sal não gerou estratégias especiais no modo de preparo da comida, mas os relatos expressaram diferenças no consumo de alimentos que muitas vezes não são al cançadas por inquéritos alimentares convencionais. Ferramentas para uma análise mais detaIhada da estrutura culinária poderiam possibilitar outros ol hares para estudos de alimentação e 
nutrição. Abordar as regras e rotinas que ocorrem na cozinha, na mesa e nas providências de abastecimento permite vislumbrar aspectos concretos esubjetivos das práticas alimentares eacessar regras sociais expressas por meio da comida.

A culinária como espaço criativo para intervenções na alimentação

Considerando que a culinária é uma prática social que funciona como um amálgama de elementos individuais ecoletivos, agrega o conhecimento tradicional e também é inovada com informações advindas de outras vivências, ela se apresenta como um espaço apropriado e promissor para intervenções que visem promover a troca de experiências eum aprendizado holístico sobre alimentação e nutrição.

A abordagem da culinária como experiência criativa para atividades que envolvem mudanças alimentares foi extraída do conceito de espaço potencial deW innicott ${ }^{28}$, portanto de um conceito originado na psicanálise. Tratar a comida sob aótica deste conceito implica conceber o potencial criativo do homem na experiência cotidiana de cozinhar. Preocupado com a relação do homem com o mundo, 0 autor introduza ideia de território intermediário no qual objetos e fenômenos transicionais representam a intermediação entre a criança e o mundo externo. É o lugar do jogo, da brincadeira, em que a ilusão e a realidadeconvivem paradoxalmente. $\mathrm{Na}$ vida adulta esta zona éa da cultura, da religião, dos rituais.

0 movimento da criatividade parte do registro cultural da humanidade, confirmando-se a cada momento na experiên cia criativa: a integração entre a originalidade e a adaptação da tradição como base da inventividade parece-me apenas mais um exemplo, e um exemplo emocionante, da ação recíproca entre separação e união ${ }^{28}$. Ao referir-se a este movimento de separação e união, 0 autor remete aos objetos e fenômenos transicionais como aqueles que podem proporcionar a continuidade ea separação entre realidade interna e externa no espaço intermediário. A inclusão da culinária, como um exercício cotidiano, neste espaço de intermediação, como um âmbito de trocas, parece ser propícia para intervenções de mudanças alimentares que habilitem a incluir a inovação e a reprodução das habilidades no manejo da comida, assim como a exteriorizar os elementos internos e a interiorizar os externos.

A transformação do alimento, além de garantir a sobrevivência, veicula uma estética pró- pria, que expressa tradições, rituais e símbolos de caráter coletivo e individual. Pela culinária, é possível preservar o passado e inovar, quando se adapta uma receita com novos ingredientes e procedimentos; éuma expressão criativa por suas infinitas possibilidades de combinação e manuseio, pela pluralidade com que um mesmo alimento é preparado, por variações em sua forma física e pela subjetividade envolvida na sua produção e naquilo que a comida representa; e por estar alocada na organização social, como uma prática social legítima, podeser considerada como um espaço criativo do cotidiano.

Por sua vez, a comida produzida tem a capacidade de reafirmação de pertencimento edeidentidade, de transmissão de afeto e outros sentimentos, mesmo quando associada a elementos de inovação, quer seja nas formas de preparo, quer nos ingredientes, pois detém os princípios próprios de identidade e de reconhecimento por seus sabores.

\section{A culinária como espaço de vivência e reflexão sobrea relação com a comida}

Um método educativo em quea culinária foi adotada como eixo estruturante das atividades desenvolvidas, equefoi delineado e experimentado recentemente em nosso país, é aqui relatado como um exemplo de experiência concreta da adoção da culinária como espaço criativo para intervenções na alimentação com vistas à promoção da alimentação saudável ${ }^{29}$. Esse método foi concebido como produto do projeto "Culinária, Saúde e Prazer", tendo sido experimentado com profissionais da atenção básica de saúde e do ensino fundamental, entre outros. Consiste em oficina educativa estruturada em quatro etapas. A primeira, denominada "Vivência Culinária", objetiva proporcionar a vivência do cozinhar como experiêncialúdica, criativa ecompartilhada. U ma dinâmica de aquecimento propicia aos participantes o contato sensorial com os alimentos. Em seguida, divididos em pequenos grupos, eles criam, juntos, pratos saudáveis sem receitas preestabelecidas, utilizando ingredientesselecionados previamente pel os coordenadores da atividade. A degustação coletiva das preparações é a atividade seguinte, entremeada pela troca de ideias sobre a experiência vivida, sendo levantadas e sistematizadas as impressões gerais dos participantes em relação a esta atividade.

Nesses procedimentos são mobilizados conhecimentos sobre culinária, exercitados nas pre- 
parações propostas pelos participantes com os alimentos adquiridos e que possibilitam uma aproximação e maior familiaridade com tais alimentos. Uma bagagem de experiências sensoriais permite avaliá-los e apreciá-los - e, uma vez que os alimentos foram manipulados e experimentados, condição bem mais favorável do que a informação verbal ou escrita para sua incorporação na alimentação, poderão ser parte do repertório culinário dos participantes. $A$ atividade desenvolvida em grupo e, emergindo nela, a discussão sobre o papel de cozinhar em família como uma oportunidade de convívio entre seus membros reforçam o papel que a culinária tem de agregar pessoas. Incentivar a distribuição desta tarefa na família certamente é uma estratégia facilitadora para a incorporação dealimentos mais saudáveis na sua rotina.

A segunda etapa, realizada imediatamente após a degustação, consiste no debate entre os participantes sobre a relação entre culinária, saúdeeprazer, utilizando-sea técnica degrupo focal. Esse debate é gravado e transcrito, e o material daí sistematizado subsidia a terceira etapa, denominada "Temperando Conceitos", realizada algumas semanas depois da etapa anterior. Nela são aprofundados teoricamente os temas surgidos no debate, sendo fornecida bibliografia sobre eles. Entre os temas que surgem recorrentemente, estão: direito humano à alimentação, alimentação no contexto contemporâneo, alimentação e cultura, alimentação e saúde, culinária e prazer.

A quarta etapa, realizada também com intervalo de semanas, visa avaliar a experiência educativa proposta e suas repercussões na vida pessoal e profissional dos participantes.

$\mathrm{Na}$ avaliação dos profissionais que participaram da experimentação do método, este Ihes proporcionou motivação, reflexão, ampliação da consciência sobre sua relação com a comida no cotidiano, aprendizado conceitual, estímulo ao desenvolvimento de habilidades culinárias e de recursos para as escolhas e práticas alimentares cotidianas e para a atuação profissional no campo da promoção da alimentação saudável.

Tal oportunidade de refletir e conceituar esta prática e relacioná-la a elementos tão essenciais como saúde e prazer reforça a experiência de cozinhar, associando a ela elementos de valor para a vida familiar. Por fim, cabe dizer que esse método tem sido replicado, na íntegra ou parcialmente, em diferentes contextos e com diferentes públicos, mostrando que é factível como estratégia educativa.

\section{Consideraçõesfinais}

Este breveensaio sobrea culinária como objeto de estudo do campo de alimentação e nutrição e de intervenções que visem a mudanças alimentares foi uma provocação para investigações que ampliem seus usos, para a construção de instrumentos que permitam acessar características da estrutura culináriae suas implicações nutricionais epara explorar o potencial desta prática, de certa maneiranegligenciada como objeto científico.

\section{Colaboradores}

RW Diez-Garcia participou da concepção eredação do artigo e desenvolveu o estudo qualitativo voltado para análise do consumo alimentar, com sujeitos submetidos à restrição de sal; IRR Castro também participou da concepção e redação do artigo e desenvolveu o estudo de intervenção utilizando a culinária como eixo estruturante de um método educativo para a promoção da alimentação saudável. 


\section{Referências}

1. Fernandez-Armesto F. Comida: uma história. Rio de Janeiro: Record; 2004.

2. Ritchie CA. Comida y civilización. Madrid: Alianza Editorial; 1986.

3. Flandrin JL, M ontanari M. História da alimentação. São Paulo: Estação Liberdade; 1998.

4. Wrangham R, Conklin-Brittain NL. Cooking as a biological trait. Comparative Biochemistry and Physiology Part A 2003; 136:35-46.

5. Fieldhouse P. Food and nutrition: customs and culture. London: Chapman \& Hall; 1996.

6. Kinouchi O, Diez-Garcia RW, Holanda AJ, Zambianchi $P$, Roque $A C$. The non-equilibrium nature of culinary evolution. N ew J. Phys 2008; (10):1-15.

7. Messer E. Perspectivas antropológicas sobre la dieta. In: Contreras J, organizador. Alimentación y cultura: necessidades, gostos y costumes. Barcelona: Publicaciones Universitat de Barcelona; 1995. p. 27-81.

8. Harris M. Bueno para comer. Madrid: Alianza; 1989

9. Contreras-H ernández J, Gracia-Arnáiz M. Alimentación y cultura: perspectivas antropológicas. BarceIona: Ariel; 2005.

10. Goody J. Cocina, cuisine y clase. Barcelona: Gedisa 1995.

11. Contreras-Hernández J. Antropologia de la alimentación. M adrid: Eudema; 1993.

12. Carrasco-i-Pons S. Pontos de partida teórico-metodológicos para o estudo sociocultural da alimentação em um contexto de transformação. In: Canesqui A, Diez-Garcia RW, organizadores. Antropologia e nutrição: um diálogo possível. Rio de Janeiro: Editora Fiocruz; 2005. p. 101-128.

13. Garcia RWD. Notas sobre a origem da culinária: uma abordagem evolutiva. Rev Nutr 1995; 8(2):231244.

14. Lévi-Strauss C. 0 cru e o cozido. São Paulo: Brasiliense; 1991.

15. Willett W. Nutritional epidemiology. New York Oxford University Press; 1990.

16. Rozin P, Vollmecke TA. Food likes and dislikes Annual Review of Nutrition 1986; 6:433-456.

17. Fischler C. El (h)omnívoro- el gusto, la cocina y el cuerpo. Barcelona: Editorial Anagrama; 1995.

18. Gazzaniga MS, Heatherton TF. Ciência psicológica: mente, cérebro e comportamento. Porto Alegre: Artmed; 2005.
19. Shepherd GM. Smell images and the flavors system in the human brain. N ature 2006; 444(7117):316-321.

20. N etto CRS. Paladar: gosto, olfato, tato e temperatura - fisiologia e fisiopatologia. São Paulo: Funpec; 2007.

21. Brillat-Savarin J.-A. A fisiologia do gosto. Rio de Janeiro: Salamandra; 1989.

22. This H. A ciência na cozinha, 2: Hervé This e os fundamentos da gastronomia molecular: corpo, máquina de comer. Scientific American. São Paulo: Duetto; 2007.

23. Bourdieu P. Esboço de uma teoria da prática. In: Ortiz R, organizador. Pierre Bourdieu. São Paulo: Ática; 1983. p. 46-81.

24. Garcia RWD. A comida, a dieta, o gosto: mudanças na cultura alimentar urbana. São Paulo: Instituto de Psicologia, USP; 1999.

25. Garcia RWD. Representações sobre consumo alimentar e suas implicações em inquéritos alimentares: estudo qualitativo em sujeitos submetidos à prescrição dietética. Rev Nutr 2004; 17(1):15-28.

26. Canesqui AM. A qualidade dos alimentos: análise de algumas categorias da dietética popular. Rev Nutr 2007; 20(2):203-216

27. Sociedade Brasileira de Cardiologia. V Diretrizes Brasileiras para Hipertensão Arterial. Arq Bras Cardiol 2007; 89(3):e24-e79.

28. Winnicott DW. 0 brincar e a realidade. Rio de Janeiro: Imago; 1975.

29. Castro IRR, Souza TSN, Maldonado LA, Caniné ES, Rotenberg S, Gugelmin SA. A culinária na promoção da alimentação saudável: delineamento e experimentação de método educativo dirigido a adolescentes e profissionais das redes de saúde e de educação. Rev Nutr 2007; 20(6):571-588.

Artigo apresentado em 10/02/2010

Aprovado em 20/05/2010

Versão final apresentada em 12/07/2010 